ISSN: 1838-2959

Volume 1, Number 1, pp. 100-105

July - 2010

\title{
Communicating with first year students; so many channels but is anyone listening? A Practice Report
}

Jason Lodge

Student Business Services

Queensland University of Technology

\begin{abstract}
Communicating with first year students has become a far more complex prospect in the digital age. There is a lot of competition for limited attentional resources from media sources in almost endless channels. Getting important messages to students when there is so much competing information is a difficult prospect for academic and professional divisions of the university alike. Students' preferences for these communication channels are not well understood and are constantly changing with the introduction of new technology. A first year group was surveyed about their use and preference for various sources of information. Students were generally positive about the use of social networking and other new online media but strongly preferred more established channels for official academic and administrative information. A discussion of the findings and recommendations follows.
\end{abstract}

\section{Please cite this practice report as:}

Lodge, J. (2010). Communicating with first year students; so many channels but is anyone listening? A Practice Report. The International Journal of the First Year in Higher Education, 1(1), $100-105$.

This practice report has been accepted for publication in Int J FYHE. Please see the Editorial Policies under the 'About' section of the Journal for further information.

(C) Copyright of practice reports is retained by the author/s. As an open access journal, practice reports are free to use, with proper attribution, in educational and other non-commercial settings. ISSN: $1838-2959$ 


\section{Background}

\section{New technologies}

The landscape of the higher education, like so many other aspects of life, has changed drastically with the new information revolution. The revolution is leading to large-scale changes in the classroom, with a plethora of new technologies being introduced to improve student outcomes (Nora \& Snyder, 2009). Podcasts of lectures, learning management systems, wikis, blogs, social networking and so on are all being adopted not only in distance education but now also finding extensive use in on-campus courses throughout the world. The "chalk and talk" pedagogy of traditional university teaching is rapidly becoming a thing of the past. Despite the widespread adoption of e-learning technologies, it has often been the case that institutions have only adopted some technologies so as not to be left behind in an increasingly competitive market (Govindasamy, 2002). Selwyn (2007) argues that this mass adoption of new technology in this manner has been haphazard and "low level" in nature and that the full potential of these new technologies is being lost in the rush to keep up with the latest technological trend. Further to this, it appears that the question becomes an issue of whether the new tool does something better and not about whether it can be integrated with existing processes, which should be the more pressing concern (Goodyear \& Ellis, 2008). Adopting new technology too enthusiastically has led to a situation where there is a multitude of parallel channels being used for communication between an institution and students and many of the messages are not getting through. This situation appears to have come about because universities are adopting these communication channels without necessarily understanding the consequences of their use (Cheung \& Huang, 2005). It is not uncommon to see various academic and administrative organisational units of a single university having a presence on Facebook, Twitter, using email alerts, RSS feeds and this all exists on top of the more established methods of broadcast emails, websites, posters around campus and information sent via the postal system. It is difficult to know which of these channels are effective, whether students are paying any attention to some of these channels and which is best for different types of messages.

\section{The issues surrounding communication with first year students}

Communicating with first year students in particular poses unique challenges. Increasingly diverse cohorts of students are entering higher education and this poses difficulties in ensuring that the communication needs of all students are met (Jeffrey, 2009). Amongst these students are the "Millennials" who have grown up in the digital age and require a different approach to communicate with than do Gen-Xers or Baby Boomers (Oblinger, 2003). Ashraf (2009) has argued that this generation are "always on/never off" and require learning environments and communication channels that are operating 24 hours a day 7 days a week. As opposed to their predecessors, Millennials also expect rapid retrieval of information, are adept at multitasking, predominantly use technology for social and professional communication and require active involvement in learning (Frand, 2000). More established methods of getting through to first years may work for older students but Millennials have no tolerance for delay and a strong need to remain connected at all times (Oblinger, 2003). This has driven the necessity for more immediate and ongoing access to information from the institution and is behind the adoption of social networking and micro-blogging as a means of keeping the communication channels open. 
As these channels of communication continue to expand and new technologies become available, it has made the task of getting messages, whether they are related to learning or administration, far more complicated. In their extensive study of the technological experiences of first year students in Australia, Kennedy, Judd, Churchward, Gray and Krause (2008) found marked variety amongst these students in terms of their use of technology. While a proportion of students are "digital natives" this does not appear to be ubiquitous amongst the population of first years, nor even amongst Millennials. This suggests that an approach that adopts new technologies at the expense of more established online communication would disadvantage some students who do not have the same level of technological skill and information literacy (Kennedy et al.). As the methods for communication grow, so does the uncertainty over which methods work best for the diverse range of students in first year cohorts; better for some is not necessarily going to be better for others.

\section{The current research}

\section{Introduction}

In order to effectively understand whether any or all of these new technologies are improving the university experience, it is essential to gauge the students' perceptions and preferences (Jara \& Mellar, 2010; Milliken \& Barnes, 2002). The current study was aimed at examining the preferences students have for various communication channels and to determine what their typical pattern of usage is. This study builds on the research conducted by Kennedy et al. (2008) by looking more closely at the now well-established social networking options for communication and at specific differences between age groups.

\section{Methods}

Students in two first year psychology subjects were surveyed online and given the opportunity to participate in focus groups. Students were offered subject credit points for participating in this research. Overall 122 students completed the survey and 57 participated in focus groups. The online survey included a number of questions about students' usage of social networking in particular as it appears to be the media that has seen the greatest increase in adoption over the last few years. The second section of the survey focussed on students' preferences for sending and receiving messages about administrative and academic issues.

\section{Results and discussion}

The results of this research indicate that the use of social networking sites amongst this group of students is much higher than that found by Kennedy et al. (2008) with $80.4 \%$ using social networking sites at least a few times a week and $90.7 \%$ having Facebook profiles. Additionally, 59.6\% reported using social networking sites at least once a day with $10.9 \%$ reporting that they use social networking sites "many times a day." None of the students surveyed reported regularly using Twitter with small numbers using blogging sites $(3.1 \%)$ or being actively involved with wikis (4.1\%). Strangely, as it was a subject requirement, only $19.6 \%$ reported regularly using the university's online learning management system.

A reasonable proportion of students $(29.9 \%)$ used social networking to get to know other students in their class. Sixty-five percent of students stated that they thought social networking is useful for communicating informal university related messages, with only 
$5.1 \%$ categorically saying they did not think it was a good idea. Overall $94 \%$ of students believe that social networking is useful as a tool for collaboration between students.

When it comes to broader preferences for communication with the university, the response tendencies are shown in Table 1.

Table 1 Students' preferences for various forms of communication

\begin{tabular}{ccccc}
\hline & Email & Face-to-face & Telephone & Social networking \\
\hline Assessment issues & $51.7 \%$ & $46.3 \%$ & $1.3 \%$ & $0.7 \%$ \\
$\begin{array}{c}\text { General academic } \\
\text { issues }\end{array}$ & $58.0 \%$ & $42.0 \%$ & $0.0 \%$ & $0.0 \%$ \\
Enrolment issues & $29.4 \%$ & $50 \%$ & $20.6 \%$ & $0.0 \%$ \\
Other admin issues & $24.6 \%$ & $49.5 \%$ & $26.2 \%$ & $0.7 \%$ \\
Career information & $26.3 \%$ & $59.4 \%$ & $13.5 \%$ & $0.8 \%$ \\
$\begin{array}{c}\text { Communicating with } \\
\text { other students }\end{array}$ & $16.6 \%$ & $31.8 \%$ & $26.8 \%$ & $24.8 \%$ \\
\hline
\end{tabular}

The messages that came out of the survey were reflected in the comments raised during the focus group sessions. Students were generally positive when asked if they thought it was useful for the institution to have a presence on social networking sites but preferred to rely on face-to-face contact or talking to someone on the telephone, particularly if the issue is administrative in nature. Interestingly, this pattern of responses was not limited to any one age group. Students born before 1970 were generally less likely to use social networking and less likely to be favourable about it being used by the university but this difference was not as sizeable as anticipated. Generally the pattern of responses did not markedly differ between people born before 1970, those born between 1970 and 1980 and those born after 1980 .

The focus group sessions also revealed a few other issues. Several students voiced concerns about privacy and being "sledged" on a public domain such as a social networking site. In this vein, a number of students expressed a preference for communicating via existing collaborative tools such as a learning management system. Although they would rather receive an email or talk to someone face to face when it comes to most issues, they did mention that Facebook, Twitter etc. are useful for sending reminders to students. These reminders however, need to be short and to the point otherwise they would not read them.

Overall it appears that usage of social networking amongst students has greatly increased over the course of a few years. Despite students predominantly stating that they think it is useful, they prefer not to communicate with or receive communication from the university about academic or administrative issues via this medium. When it comes to important messages from the university, it appears that social networking etc. is useful for sending reminders but generally they would like to continue to receive important messages via email or directly from teaching and/or administrative staff. 


\section{Recommendations}

- Formal messages that require more detail are best left to more established methods of communication.

- Social networking may be a great tool to help students develop peer relationships and increase student engagement.

- Short, sharp messaging like that used in Twitter, status feeds in Facebook and RSS feeds are best for reminders - anything over 1 or 2 lines is not being read.

- Older students (Gen-Xers and Baby Boomers) seem to be catching up with the Millennials in terms of their use of new technology. Many now have Facebook profiles so the use of these tools for specific purposes outside the formal curriculum may be more useful.

- Millennials might or might not be "digital natives"; either way they prefer email or face-to-face communication in many cases.

\section{Outcomes of discussion and reflections}

The results of this study appear to be a reflection of common experiences at other institutions. The problem of communicating necessary information to students is exacerbated by a number of factors. Firstly, it is necessary to ensure that students clearly understand their rights and obligations. The common experience seems to be that students are being swamped by a tsunami of competing information and many of these important messages are being missed. The challenge for academic and professional staff alike is to manage and coordinate the communications being sent to students. Additionally, it is imperative that institutions package this information in a way that students will be motivated and able to engage with. Although it would be easy to dismiss this as an obligation students have to the institution, getting the communication strategy right also has the potential to create savings in terms of the support required for students who do not readily understand what they need to do.

In terms of some of the new innovations in communication, there is some variation in the experiences between institutions. Although a large number of students both mature-aged and school leavers appear to be actively using social networking, the use of online learning management systems and micro-blogging sites such as Twitter varies considerably. The relative levels of success with social networking appear to rely on the ability of the institution to carefully tailor messages sent out using this medium. Social networks are predominantly used for socialising; it is the students' realm so students are under no obligation heed any incursions by the institution into this space and therefore messages are being ignored.

The channels for communicating with students going forward are likely to continue to increase. This will create even more difficulty in ensuring that students are getting and understanding the information they need in order to navigate their way through the first year of university. The ways in which technology is rapidly changing the nature of higher education in general necessitates careful consideration of the implications of this technology on the first year experience. New technology and options for communication are only valuable when the necessary messages are getting through.

\section{References}


Ashraf, B. (2009). Teaching the Google-eyed YouTube generation. Teaching \& Education, 51, 343-352.

Cheung, W. \& Huang, W. (2005). Proposing a framework to assess internet usage in university education: An empirical investigation from a student's perspective. British Journal of Educational Technology, 36, 237-253.

Frand, J. L. (2000). The information-age mindset. Changes in students and implications for higher education. Educause Review, 35, 15-24.

Goodyear, P. \& Ellis, R. A. (2008). University students' approaches to learning: Rethinking the place of technology. Distance Education, 29, 141-152.

Govindasamy, T. (2002). Successful implementation of e-learning: Pedagogical considerations. Internet and Higher Education, 4, 287-299.

Jara, M. \& Mellar, H. (2010). Quality enhancement for e-learning courses: The role of student feedback. Computers and Education, 54, 709-714.

Jeffrey, L. M. (2009). Learning orientations: Diversity in higher education. Learning and Individual Differences, 19, 195-208.

Kennedy, G., Judd, T., Churchward, A., Gray, K., \& Krause, K-L. (2008). First year students' experiences with technology: Are they really digital natives? Australasian Journal of Educational Technology, 24, 108-122.

Milliken, J. \& Barnes, L. P. (2002). Teaching and technology in higher education: Student perceptions and personal reflections. Computers and Education, 39, 223-235.

Nora, A. \& Snyder, B. P. (2009). Technology and higher education: The impact of e-learning approaches on student academic achievement, perceptions and persistence. Journal of College Student Retention, 10, 3-19.

Oblinger, D. G. (2003). Boomers, Gen-Xers and Millennials: Understanding the new students. Educause Review, 38, 37-47.

Selwyn, N. (2007). The use of computer technology in university teaching and learning: A critical perspective. Journal of Computer Assisted Learning, 23, 83-94. 